$\xi_{p}$

\title{
Physicochemical Properties of Palm Kernel Oil and Palm Kernel Olein Blends
}

\author{
Norizzah Abd Rashid ${ }^{1 *}$, Fatin Nurhanis Jumari ${ }^{1}$, Zaliha Omar ${ }^{2}$ \\ ${ }^{1}$ Faculty of Applied Sciences, Universiti Teknologi MARA, 40450 Shah Alam, Selangor, Malaysia \\ ${ }^{2}$ Malaysian Palm Oil Board (MPOB), No. 6 Persiaran Institusi, Bandar Baru Bangi, 43000 Kajang, Selangor \\ *Corresponding author E-mail: norizzah850@salam.uitm.edu.my
}

\begin{abstract}
Palm kernel oil (PKO) and palm kernel olein (PKOo) have limited application due to rapid crystallisation properties and excessive foaming during heating, respectively. In this study, a series of PKO and PKOo blends were prepared at different concentration and analysed for slip melting point (SMP), solid fat content (SFC), triacylglycerols (TAGs) composition, thermal and morphological properties. The addition of $90 \%$ RBDPKOo caused the SMP to decrease from $27.8^{\circ} \mathrm{C}$ to $23.80^{\circ} \mathrm{C}$. All the samples show steep SFC melting profile from $0^{\circ} \mathrm{C}$ to $30^{\circ} \mathrm{C}$. The onset crystallisation temperature of RBDPKO was delayed with the addition of $90 \%$ PKOo from $9.73^{\circ} \mathrm{C}$ to $5.80^{\circ} \mathrm{C}$ and totally melted at lower melting temperatures. It was observed that the addition of RBDPKOo caused the crystals to be spherulitic, scattered and less aggregated with each other. The addition of RBDPKOo reduced the compositions of the main TAG of RBDPKO such as LaLaLa, LaLaM and CLaLa. Therefore, through blending the physicochemical properties of the RBDPKO and RBDPKOo could be changed. Hence, their applications in food could be widened.
\end{abstract}

Keywords: Blending; palm kernel oil; palm kernel olein; solid fat content; thermal properties.

\section{Introduction}

Palm kernel oil (PKO) is derived from the kernel of the palm fruit. $\mathrm{PKO}$ is a relatively firm at room temperature and totally melted at $27-30^{\circ} \mathrm{C}[1]$. Palm kernel oil known as lauric oils because it has high content of lauric acid (C12:0) [2]. The high composition of lauric acid in PKO makes this oil has sharp melting properties [3]. The specific fatty acid composition gives unique melting characteristics that makes PKO widely used as specialty fat in food industry [4]. The different between PKO and other commercial oils is that PKO exhibits high oxidative stability that makes it more valuable oil and has a good quality [5]. PKO is widely applied in food products because its exhibit easy absorbability and digestibility due to high content of medium chain fatty acids (MCFA) [3]. It is suitable for application in fat-structured food like ice cream, cocoa butter substitutes and margarine [3, 6]. Palm kernel oil can be fractionated to solid fraction (palm kernel stearin) and liquid fraction (palm kernel olein). Palm kernel olein (PKOo) is suitable for application in food products as a lauric based liquid coating of ice cream which solidified faster on ice cream during dipping and as spray oil in biscuit or snack manufacturing [7]. However, palm kernel oil and palm kernel olein have limited application due to fast crystallisation properties and excessive forming during heating, respectively [8]. PKO and PKOo needs to undergo modification process either physically or chemically to increase the usage of this oil. The blending of these oils allows the combination of the properties which could widen the usage of the oils. The physical and chemical composition of the vegetable oils can be tailored to meet certain characteristics depends on the product that might be produced. In this study, palm kernel oil was mixed with palm kernel olein at different ratios and the physicochemical properties of the blends were analysed for slip melting point (SMP), solid fat content (SFC), thermal properties, crystal morphology and triacylglycerols composition (TAGs). Data obtained from this study could contribute to a greater understanding on the effect of blending towards crystallisation and melting properties of these oils.

\section{Materials and methods}

\subsection{Materials}

Refined, bleached and deodorised palm kernel oil (RBDPKO) and palm kernel olein were obtained from Mewah Oleo Sdn. Bhd., Klang, Selangor, Malaysia. The oils were stored at $0^{\circ} \mathrm{C}$ prior to use.

\subsection{Methods}

RBDPKO and RBDPKOo were melted at $70^{\circ} \mathrm{C}$ for 30 minutes and thoroughly stirred to destroy all the crystal memory before being mixed to form a series of blends as shown in Table 1. The blends were analysed for slip melting point, solid fat content, thermal properties, crystal morphological and triacylglycerols composition.

Table 1: Labelled of RBDPKO, RBDPKOo and their blends.

\begin{tabular}{ccc}
\multirow{2}{*}{ RBDPKO } & \multirow{2}{*}{ RBDPKOo } & Label \\
\cline { 3 - 3 } & 0 & RBDPKO:RBDPKOo \\
90 & 10 & $100: 0$ \\
80 & 20 & $90: 10$ \\
70 & 30 & $80: 20$ \\
60 & 40 & $70: 30$ \\
\hline
\end{tabular}




\begin{tabular}{ccc}
\hline 50 & 50 & $50: 50$ \\
40 & 60 & $40: 60$ \\
30 & 70 & $30: 70$ \\
20 & 80 & $20: 80$ \\
10 & 90 & $10: 90$ \\
0 & 100 & $0: 100$ \\
\hline
\end{tabular}

\subsection{Slip Melting Point (SMP)}

The slip melting point of the oils and blends were carried out according to AOCS Method Cc.3.25 [9]. Capillary tubes (i.d. 1.1-1.3 $\mathrm{mm}$; o.d. $1.4-1.7 \mathrm{~mm}$; 50-60 mm length) were filled with a $1 \mathrm{~cm}$ high column of oil. The capillary tubes were then rolled against a piece of ice before being chilled in a refrigerator at $10 \pm 1^{\circ} \mathrm{C}$ for 16 $\mathrm{h}$ to solidify the fat. The tubes were subsequently attached with a rubber band to a thermometer and suspended in a $600 \mathrm{ml}$ beaker of boiled distilled water. The bath temperature was adjusted $8-10^{\circ} \mathrm{C}$ below the slip melting point of the oil and heat was applied using a heating coil element to increase the bath temperature at a rate of $1{ }^{\circ} \mathrm{C} / \mathrm{min}$. A magnetic stirrer was used to stir the water. The temperature at which the fat column rises was recorded as the SMP. The SMP of the oils and blends were carried out in triplicate and the mean values were calculated.

\subsection{Solid Fat Content (SFC) by pulsed Nuclear Mag- netic Resonance (pNMR)}

The percent $(\%)$ solid fat content of oils and blends were measured as a function of temperature according to MPOB Test Method [10]. Calibration was performed using standards provided by Bruker. Samples were melted at $70^{\circ} \mathrm{C}$ for 30 minutes to destroy all crystal memory. Approximately $3.0 \mathrm{~g}$ of melted oils and blends were pipetted into pulsed pNMR tubes $(10.0 \mathrm{~mm}$ diameter, 1.0 $\mathrm{mm}$ thickness and $180 \mathrm{~mm}$ height). The tubes were chilled at $0^{\circ} \mathrm{C}$ for 90 minutes and kept for 30 minutes at the desired temperatures prior to measurements. The measurements were carried out using the pulsed Nuclear Magnetic Resonance (pNMR) spectrometry (Bruker minispec P20:20 Mhz, Karlsruhe, Germany). The measurement was carried out in duplicates.

\subsection{Thermal properties by Differential Scanning Calorimeter (DSC)}

The thermal properties of the oils and their blends were measured by Differential Scanning Calorimeter (DSC) (Perkin-Elmer, Norwalk, CT). The instrument was calibrated by an indium standard for the high temperature range and n-decane for sub-ambient temperature range. About 3-5 mg of samples were weighed and hermetically sealed in aluminum pans with an empty pan as a reference. The sample was heated to $80^{\circ} \mathrm{C}$ for $10 \mathrm{~min}$ to erase the crystal memory. The sample was cooled from melt $\left(80^{\circ} \mathrm{C}\right)$ at $5^{\circ} \mathrm{C} / \mathrm{min}$ to $-40^{\circ} \mathrm{C}$ and held for $10 \mathrm{~min}$ before being reheated to $80^{\circ} \mathrm{C}$ at $5^{\circ} \mathrm{C} / \mathrm{min}$. Both the cooling and melting thermograms were recorded.

\subsection{Crystal Morphology by Polarised Light Microscope}

The crystal morphology of oils and blends was determined by Polarised Light Microscope (PLM) equipped with a Linkam THSM 600 temperature controller stage and a JVC 3-CCD colour video camera. Temperature was thermostatically controlled by a LINKAM TP 94 multiramp temperature programmer and LNP cooling system. Liquid nitrogen was used as a coolant. A small droplet of sample was placed on a glass slide and covered with glass slip. Then, the slide was placed on sample temperature controlled-stage and 200x magnification was used to capture the image of the crystal at $20^{\circ} \mathrm{C}$.

\subsection{Triacylglycerols composition (TAGs)}

The AOCS method 5c-93 [9] was used to analyse the TAG profiles for RBDPKO, RBDPKOo and their blends by a reversephase High Performance Liquid Chromatography (Gilson, Villiers-e-bel, France). A Lichrosphere RP-18 column (250 mm x 4 $\mathrm{mm})$ with $5 \mu \mathrm{m}$ particle size (Merck, Darmstadt, Germany) was used with a mixture of acetone / acetonitrile $(75: 25 \% \mathrm{v} / \mathrm{v})$ as the eluent at a flow rate of $1.0 \mathrm{ml} / \mathrm{min}$ using a refractive index detector. The reproducibility and repeatability of the HPLC was tested by running triplicates of RBDPKO sample. Identification of TAG species was performed by comparing the retention times of the TAG of the analysed oils with that of commercial TAG standards.

\subsection{Statistical analysis}

Selected data obtained were analysed statistically using one-way ANOVA with the aid SPSS software version 18. The significance differences among mean values was identified at a level of $95 \%$ $(\mathrm{p}<0.05)$.

\section{Results and discussion}

\subsection{Slip melting point}

Table 2 shows the SMP of the RBDPKO, RBDPKOo and their blends at different concentrations. Results indicated that the $\mathrm{RBDPKO}$ has melting point of $27.80^{\circ} \mathrm{C}$ while RBDPKOo has the lowest melting point of $23.0^{\circ} \mathrm{C}$. The addition of $90 \%$ of RBDPKOo significantly decreased $(\mathrm{p}<0.05)$ the SMP of the blend from $27.80^{\circ} \mathrm{C}$ to $23.80^{\circ} \mathrm{C}$. The lower value of the SMP is due to the unsaturation of the olein in the blends. The presence of liquid fraction in the oil caused the SMP of the blend to decrease. The changes in SMP is due to the changes in TAGs composition of the blends as shown in Table 3 .

Table 2: Slip melting point $\left({ }^{\circ} \mathrm{C}\right)$ of RBDPKO:RBDPKOo blends.

\begin{tabular}{cl}
\hline RBDPKO:RBDPKOo & Slip Melting Point $\left({ }^{\circ} \mathbf{C}\right)$ \\
\hline $100: 0$ & $27.80 \pm 0.2^{\mathrm{ab}}$ \\
$90: 10$ & $27.47 \pm 0.50^{\mathrm{abc}}$ \\
$80: 20$ & $28.10 \pm 0.10^{\mathrm{a}}$ \\
$70: 30$ & $27.00 \pm 1.00^{\mathrm{abc}}$ \\
$60: 40$ & $26.73 \pm 0.25^{\mathrm{bcd}}$ \\
$50: 50$ & $25.83 \pm 0.29^{\mathrm{d}}$ \\
$40: 60$ & $26.53 \pm 0.15^{\mathrm{cd}}$ \\
$30: 70$ & $25.73 \pm 0.25^{\mathrm{de}}$ \\
$20: 80$ & $24.63 \pm 0.15^{\mathrm{ef}}$ \\
$10: 90$ & $23.80 \pm 0.10^{\mathrm{fg}}$ \\
$0: 100$ & $23.00 \pm 0.30^{\mathrm{g}}$ \\
\hline Note: ${ }^{\text {abcdefg }}$ Different letters within the column are significantly different
\end{tabular}

$(\mathrm{p}<0.05)$. Results are presented as mean values \pm SD $(n=3)$

\subsection{Solid fat content}

The melting behaviour of the oils and blends can also be described by solid fat content determination at various temperatures. The SFC is also related to the texture and plasticity of fat blends. Below a certain range of SFC, fat no longer possess plastic properties [11]. Fig. 1 shows the SFC of RBDPKO, RBDPKOo and their blends as a function of temperature. The SFC of RBDPKO, RBDPKOo and their blends declined with the increase in temperatures. The RBDPKO shows the highest SFC content at all temperatures and totally melted at $30^{\circ} \mathrm{C}$. While, RBDPKOo shows the lowest SFC content and totally melted at $25^{\circ} \mathrm{C}$. It was also noticed that the SFC of the oils and blends slowly decreased from $0-10^{\circ} \mathrm{C}$ followed by a drastic declined from $10-25^{\circ} \mathrm{C}$ (steep melting profile). In some food systems that contain fats, a high solid fat content is desirable at room temperature to promote an adequate crystalline structure and plasticity. It was reported that the low SFC at high temperatures is required to promote an easy melting in the 
mouth such as chocolate and margarines [12]. The drastic declined in SFC could also due to some of the TAGs liquefying and solubilising within this temperature. At temperature of $25^{\circ} \mathrm{C}$, there was no SFC detected for RBDPKOo and blends of RBDPKO:RBDPKOo 40:60, 30:70, 20:10 and 90:10. This is due to most of the low melting of the blends had already melted at this temperature $\left(>25^{\circ}\right)$. However, blends with 90:10, 80:20, 70:30, 60:40 and 50:50 contained 15-30\% SFC at this temperature. All the samples were totally melted at $30^{\circ} \mathrm{C}$.

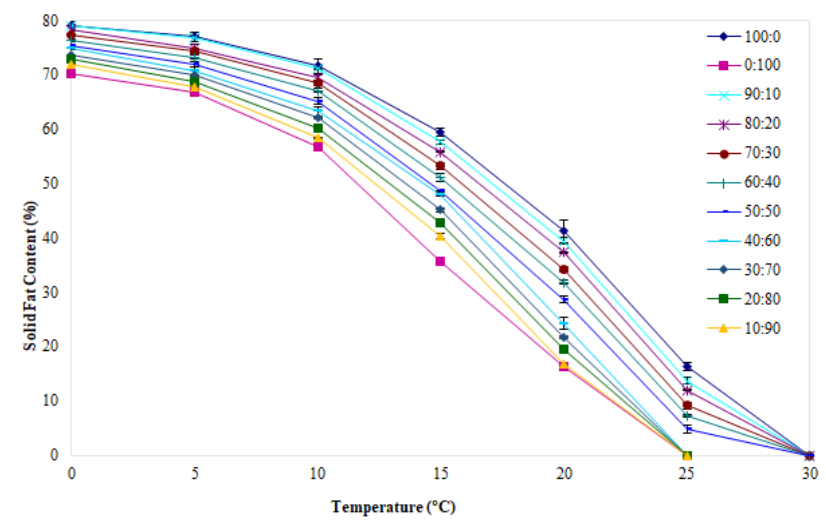

Fig. 1: Solid fat content (SFC) as a function of temperature for RBDPKO, RBDPKOo and blends

\subsection{Thermal properties}

Fig. 2 shows the DSC cooling thermograms of the samples from $80^{\circ} \mathrm{C}$ to $-40^{\circ} \mathrm{C} 5^{\circ} \mathrm{C} / \mathrm{min}$ heating rate. The thermograms of RBDPKO, RBDPKOo and their blends show the formation of two (2) prominent exothermic peaks (A and B). Addition of RBDPKOo resulted the onset crystallisation temperatures of the blends to decrease to the lower temperatures. It was also observed that both exothermic peaks of the blends were shifted to the lower crystallisations temperature. For example, the onset crystallisation temperature of RBDPKO was at $9.73^{\circ} \mathrm{C}$ with the formation of the first exothermic peak at $4.77^{\circ} \mathrm{C}$ and followed by the second peak at $1.48^{\circ} \mathrm{C}$. The exothermic heat of crystallisation $(\Delta \mathrm{Hc})$ was $92.90 \mathrm{~J} / \mathrm{g}$. The addition of higher amounts of RBDPKOo (90\%) shifted the onset crystallisation temperature from $9.73^{\circ} \mathrm{C}$ to $5.80^{\circ} \mathrm{C}$. The first exothermic peak shifted from $4.77^{\circ} \mathrm{C}$ to $1.20^{\circ} \mathrm{C}$ followed by a second peak from $1.48^{\circ} \mathrm{C}$ to $-4.12^{\circ} \mathrm{C}$. The $\Delta \mathrm{Hc}$ increased from $-92.9 \mathrm{~J} / \mathrm{g}$ to $-85.26 \mathrm{~J} / \mathrm{g}$. The sharp exothermic peaks $\mathrm{A}$ at higher temperatures are due to the higher melting triacylglycerols (TAGs) content. The broader peaks B at lower temperature due to low melting TAGs content. Therefore, the onset crystallisation of RBDPKO can be delayed by blending with RBDPKOo.

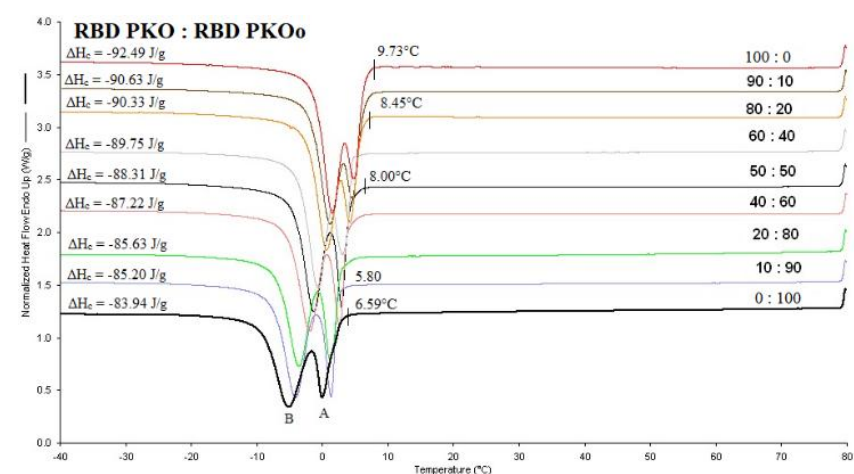

Fig. 2: DSC cooling thermograms of palm kernel oil, palm kernel olein and blends from melted $\left(80^{\circ} \mathrm{C}\right)$

The melting thermograms for endothermic peaks of the samples (melting behavior) are shown in Fig. 3. The melting thermograms show formation of small initial melting peak A followed by shoulder B with a sharp peak C. RBDPKO started to melt at $15.35^{\circ} \mathrm{C}$ (peak A) and slowly increased to form shoulder B at $13.00^{\circ} \mathrm{C}$ followed by the highest endothermic peak $\mathrm{C}$ at $26.87^{\circ} \mathrm{C}$. The RBDPKO totally melted at $30.86^{\circ} \mathrm{C}$ with the heat of fusion $\left(\Delta \mathrm{H}_{f}\right)$ of $103.48 \mathrm{~J} / \mathrm{g}$. The addition of higher amount of RBDPKOo (50\%-90\% caused peak A of the blends started to melt at same temperature as RBDPKO at $-16^{\circ} \mathrm{C}$. However, the shoulder $\mathrm{B}$ and the peak $\mathrm{C}$ of the blends started to melt at lower melting temperature as compared to RBDPKO. The samples also totally melted at lower melting temperature with lower $\Delta \mathrm{H}_{f}$. Therefore, the addition of the RBDPKOo softened the samples as also shown by the reduction of SFC and SMP of the blends. Hence, blending of RBDPKO with RBDPKOo can alter the melting temperature of the blends.

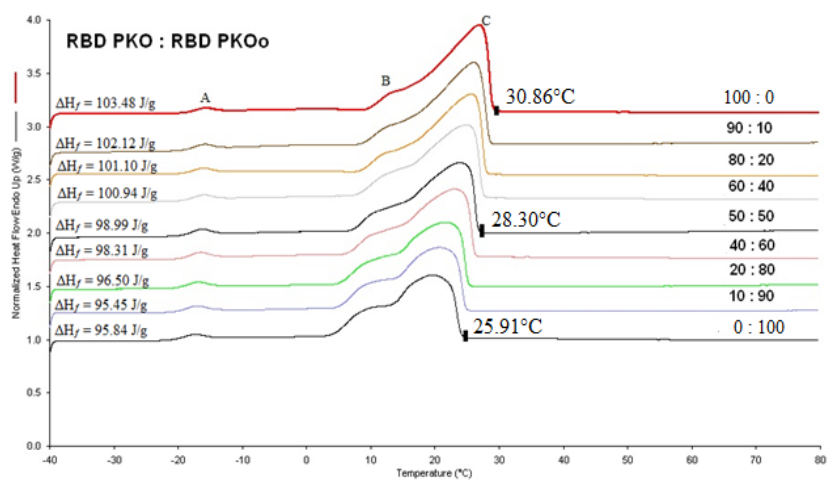

Fig. 3: DSC melting thermograms of palm kernel oil and palm kernel olein blends

\subsection{Morphological properties}

The crystal microstructures of the RBDPKO, RBDPKOo and blends are shown in Fig. 4. At $20^{\circ} \mathrm{C}$, RBDPKO crystallised to form denser, packed and highly structured crystal networks as compared to the blends. It was observed that the addition of RBDPKOo caused the crystals to be spherulitic, scattered and less aggregated with each other. Besides, the blends showed more liquid fraction in between the crystal. This is due to the dilution and liquefying effect of the RBDPKOo added. Pande and Akoh [13] reported that the small crystal causes the fat to be more firm and smooth texture or mouthfeel. While the larger crystal aggregates would produce some softer fats and may impart the grainy texture or mouthfeel to the final products.
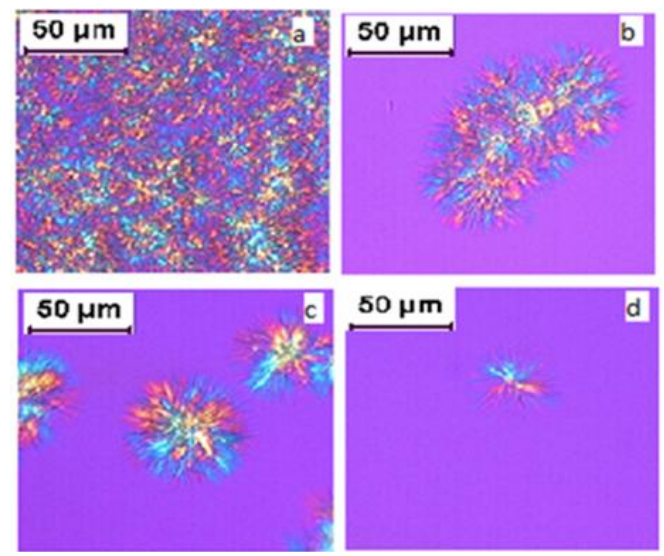

Fig. 4: Crystal morphological properties of RBDPKO:RBDPKOo blends at different composition at $20^{\circ} \mathrm{C}$ with $200 \mathrm{x}$ magnification. a. $100: 0$ b. $70: 30$ c. $50: 50$ d. 0:100.

\subsection{Triacylglycerols}

Table 3 shows the TAGs composition of RBDPKO, RBDPKOo and their blends. RBDPKO has a higher amount of medium-chain 
TAGs such as $21.85 \%$ LaLaLa (trilaurin), $16.44 \%$ LaLaM (dilauromyristin) and CLaLa (dilaurocapric). This was also reported by Norizzah et al. [14] and Zaliha et al. [15]. Blending of $90 \%$ RBDPKOo into RBDPKO caused the changes in LaLaLa, LaLaM and CLaLa composition from $21.85 \%$ to $18.95 \%, 16.44 \%$ to $13.96 \%$ and $9.75 \%$ to $10.16 \%$, respectively. On the other hand, the content of POO, PPO, LaMO increased from $1.67 \%$ to $1.98 \%, 1.01 \%$ to $1.2 \%, 5.83 \%$ to $6.61 \%$, respectively. The changes in the TAGs composition caused changes in the SFC profiles and thermal properties of the oils and blends as discussed earlier. The small changes in TAG profiles could affect the crystallisation and structure development of the fats [11].

Table 3: Triacylglycerol composition (TAG) of RBDPKO, RBDPKOo and their blends

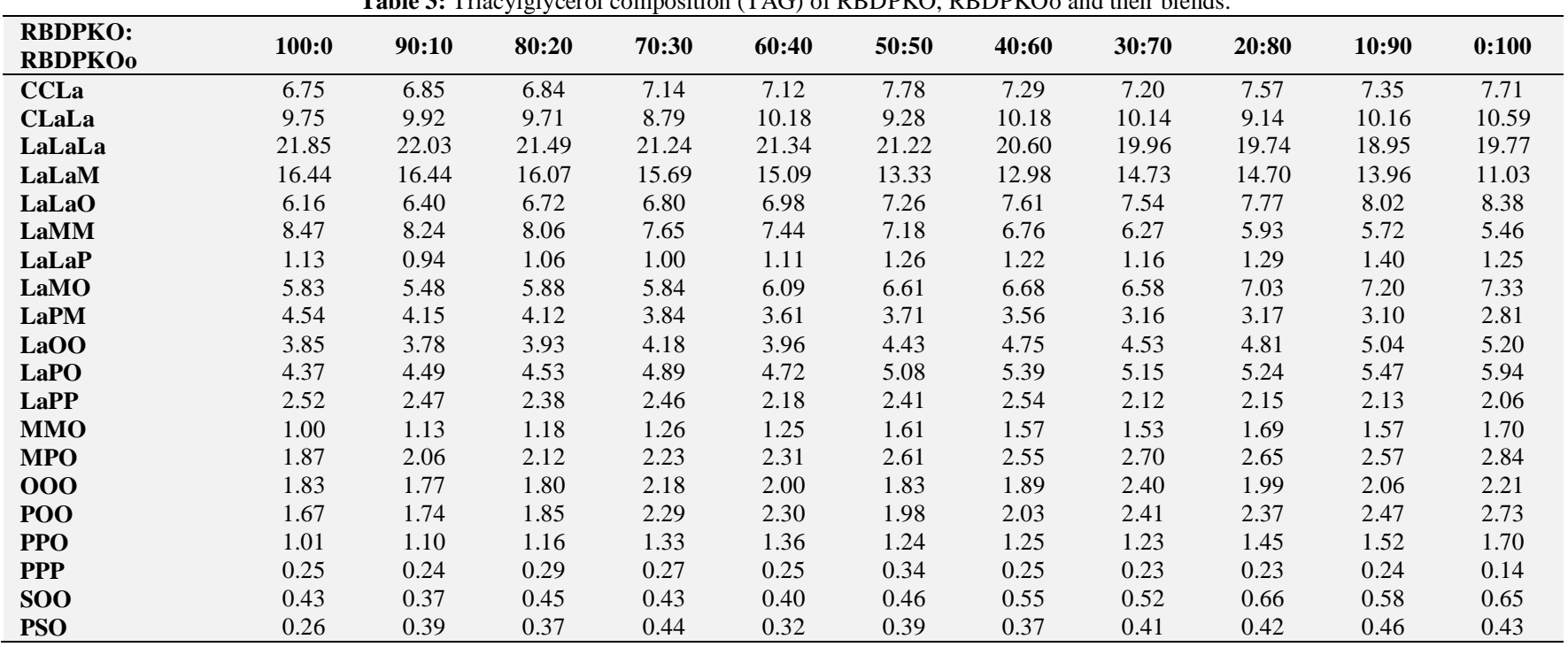

Note: Ca, caprylic acid; C, capric acid; La, lauric acid; L, linoleic acid; M, myristic acid; O, oleic acid; P, palmitic acid; S, stearic acid.

\section{Conclusion}

Blending of palm kernel olein with palm kernel oil at different concentration altered the physicochemical properties of the oils and blends such as SMP, SFC, TAGs composition and microstructural properties. This technique also delayed the DSC onset crystallisation and melting temperature of the blends. Therefore, by changing their physicochemical properties, the usage of the oils could be widened.

\section{Acknowledgements}

The authors would like to thank the financial support given by the Institute of Research Management \& Innovation (IRMI) [600IRMI/DANA 5/3(128/2018)] and facilities provided by the Faculty of Applied Sciences, Universiti Teknologi, MARA (UiTM), Shah Alam, Selangor and special thanks to all Lipid Technology Group staff of Malaysian Palm Oil Board (MPOB) for their assistance.

\section{References}

[1] Norizzah AR, Nur Azimah K \& Zaliha O (2016), Effect of chemical and enzymatic interesterification on the physicochemical properties of palm oil and palm kernel oil blends. Jurnal Teknologi 78 (11-2), 1-6.

[2] Kılıç B \& Özer CO (2017), Effects of replacement of beef fat with interesterified palm kernel oil on the quality characteristics of Turkish dry-fermented sausage. Meat Science 131, 18-24.

[3] Chai X, Meng Z, Jiang J, Cao P, Liang X, Michael P, Shawn C, Seong KL \& Liu Y (2018), Non-triglyceride components modulate the fat crystal network of palm kernel oil and coconut oil. Food Research International 105, 423-431.

[4] Zhang W, Leong SM, Zhao F, Zhao F, Yang T, Liu S (2018), Viscozyme L pretreatment on palm kernels improved the aroma of palm kernel oil after kernel roasting. Food Research International $107,172-181$
[5] Law MC, Liew EL, Chang SL, Chan YS \& Leo CP (2016), Modelling microwave heating of discrete samples of oil palm kernels. Applied Thermal Engineering 98, 702-726.

[6] Saberi AH, Kee BB, Oi-Ming L \& Miskandar MS (2011), Physicochemical properties of various palm-based diacylglycerol oils in comparison with their corresponding palm-based oils. Food Chemistry 127(3), 1031-1038.

[7] Palm Kernel Olein (2018), Cargill, Incorporated.United Stated.

[8] Norizzah AR, Chong CL, Cheow CS \& Zaliha O (2003), Effects of chemical interesterification on physicochemical properties of palm stearin and palm kernel olein blends. Food Chemistry 86, 229-235.

[9] Official and Tentative Methods of the American Oil Chemist's Society (AOCS) (1990), Champaign: American Oil Chemist's Society Press.

[10] MPOB (2005), MPOB Test Methods. Palm Oil Research Institute of Malaysia, Ministry of Primary Industries, Malaysia.

[11] Veerle DG, Vereecken J, Smith KW, Bhaggan K \& Dewettinck K (2012), Effect of TAG composition on the solid fat content profile, microstructure, and hardness of model fat blends with identical saturated fatty acid content. European Journal of Lipid Science and Technology 114(5), 592-601.

[12] Renato G, Lireny AGG, Luiz AG \& Ilka SS (2001), Interactions in interesterified palm and palm kernel oils mixtures. I-Solid fat content and consistency. Grasas y Aceites 52(6), 349-354.

[13] Pande G \& Akoh CC (2013), Enzymatic modification of lipids for trans-free margarine. Lipid Technology 25(2), 31-33.

[14] Norizzah AR, Chong CL, Cheow CS \& Zaliha O (2012), Crystallisation kinetics of palm stearin, palm kernel olein and their blends. LWT-Food Science and Technology 46, 571-573.

[15] Zaliha O, Elina H, Sivaruby K, Norizzah AR \& Marangoni AG (2018), Dynamics of Polymorphic Transformations in Palm Oil, Palm Stearin and Palm Kernel Oil Characterized by Coupled Powder XRD-DSC. Journal of Oleo Science 67(6), 1-8. 